\title{
ELECTROPHYSIOLOGICAL EVIDENCE FOR AN L-SHAPED INTERHEMISPHERIC CONNECTION IN THE CAT
}

\author{
A. CUKIERT - C. TIMO-IARIA
}

SUMMARY - Transcallosal potentials evoked by electrical stimulation with rectangular puIses of $1 \mathrm{~ms}, 5 \mathrm{c} / \mathrm{s}$ and variable intensity were recorded from the cortical surface in cats anesthetized with ketamine hydrochloride. Sites of stimulation and recording were selected by means of a cartesian map of most of the neocortex. In addition to the well known transcallosal projection pattern it was found that stimulation of a restricted posterior area evokes low voltage potentials over the contralateral symmetric area while high voltage potentials are recorded from a $f \in w$ sites located at the ipsilateral anterior cortex and from the area symmetric as to the latter. 'This L-shaped transcallosal connection may be involved in complex cortical processes and is compatible with effective results of partial anterior callosotomies in patients with multifocal epilepsy and frontal bisynchronism.

Evidência eletrofisiológica da presença de uma conexão inter-hemisférica em torma de ' $L$ ' no gato.

RESUMO - Foram obtidos potenciais evocados transcalosos por aplicação de pulsos quadrados de $1 \mathrm{~ms}, 5 \mathrm{c} / \mathrm{s}$ e intensidade variável e registro sobre a corticalidade de gatos anestesiados com quetamina. Os locais de estimulaçăo e registro eram selecionados através de mana cartesiano de grande parte do neocórtex. Além das bem conhecidas projeçōes calosas, foram discriminadas áreas posteriores cuja estimulaçāo evocava potenciais de baixa amplitude em sua área homóloga e potenciais de grande amplitude em regiōes mais anteriores, ipsi- e contralateralmente. Esta conexāo transcalosa em forma de ' $L$ ' pode estar envolvida em processos corticais complexos e é compativel aos bons resultados obtidos por calosotomias parciais anteriores em pacientes com epilepsia multifocal e bissincronia frontal.

Interhemispheric integration is part of higher cortical functional processes and intrahemispheric cortical pathways are involved in transferring information between different areas of the same side. The corpus callosum, the thickest brain commissure, has been extensively studied from the clinical and experimental points of view 1,8,9,11,13.

Besides the multitude of short such connections long pathways are well known to interconnect areas mediating processes such as speech and visuomotor integration. In experiments aiming at a detailed study of transcallosal connections in the cat 4 we found electrophysiological evidence of transfer of information from one area from one hemisphere to sites far from the contralateral symmetric area. The present paper reports the experiments that led to finding this L-shaped connection.

\section{MATERIAL AND METHODS}

Ten adult cats of either sex were anesthetized with ketamine hydrochloride and the neocortex was exposed and electrocorticographic recordings obtained according to procedures described elsewhere 4.

Laboratories of Functional Neurosurgery and Clinical Physiology, School of Medictne, University of Sāo Paulo, Brazil.

This research was supported by FAPESP (84/1078-9 and 85/3531-5), FINEP (43.86.0222.00) and LIM Institute (LIM 74-45).

Dr. Arthur Cukiert - Rua Baltazar da Veiga 367 apto. 151 - 34510 Säo Paulo SP - Brasil. 
Stimulation with rectangular pulses of variable frequency $(0.5$ to $10 \mathrm{~Hz})$, duration (0.1 to $3 \mathrm{~ms}$ ) and current $(0.5$ to $5 \mathrm{~mA}$ ) was performed through bipolar silver electrodes $0.8 \mathrm{~mm}$ in diameter, one milimiter apart. For mapping purposes only $1 \mathrm{~Hz}, 0.5 \mathrm{~ms}$ and $4 \mathrm{~mA}$ pulses were used. The other parameters were used for testing. The recording electrode was also a silver ball $0.8 \mathrm{~mm}$ in diameter.

Evoked potentials were recorded from sites along the anteroposterior parallels and then from the dorsoventral meridians, having the homologous locus at its center. For each site twenty potentials were electronically averaged. When signs of the L-shaped connection were well established experiments were performed in which some of the links involved were sectioned.

\section{RESULTS}

The potentials evoked contralaterally by stimulation of most areas in one hemisphere were, in which morphology, latency and amplitude are concerned, quite similar to those previously described 2,3,5,6. We found, however, that stimulation of a few sites located posteriorly at the marginal and suprasylvian gyri evoked small or moderate responses from the homologous contralateral areas, while larger potentials were elicited over contralateral more anterior areas, mainly in the medio-anterior region of the marginal or suprasylvian gyri (Fig. 1). These responses were evoked from areas poorly interconnected by the corpus callosum 7 .

To check the oresence of an intrahemispheric connection that might account for these potentials three types of experiments were performed. 1 . While stimulating one of the areas poorly interconnected by callosal neurons (S in Fig. 2 - Left) potentials were recorded from the symmetric area (R1) and from the anterior site where a higher amplitude potential had been recorded (R2). Two percortical sections (which included the subjacent white matter) were made with a sharp knife, the first medial and the second anterior to $\mathbf{S}$. After the first section (1 in Fig. 2 - Left) was performed the evoked potential in $R 1$ completely disappeared whereas that evoked in the anterior region (R2) was only slightly reduced. After sectioning at site 2, the more anterior evoked potential (R2) was abolished. 2. In the second type of experiment serial sections (numbered 1,2 and 3 in Fig. 2 - Middle) were made in the hemisphere being stimulated. Sections 1 and 2 were anterior to the $R 2$ meridian while section 3 was done between the R1 and R2 meridians. Sections 1 and 2 did not modify $R 2$ potentials and section 3 , as expected from experiment 1 , abolished the response. 3. Intrahemispheric evoked potentials showed that stimulation at $\mathrm{S}$ (Fig. $\mathbf{2}-$ Right) caused much larger potentials in site R2' than when stimulation was performed at R2' and potentials recorded from $\mathbf{S}$.
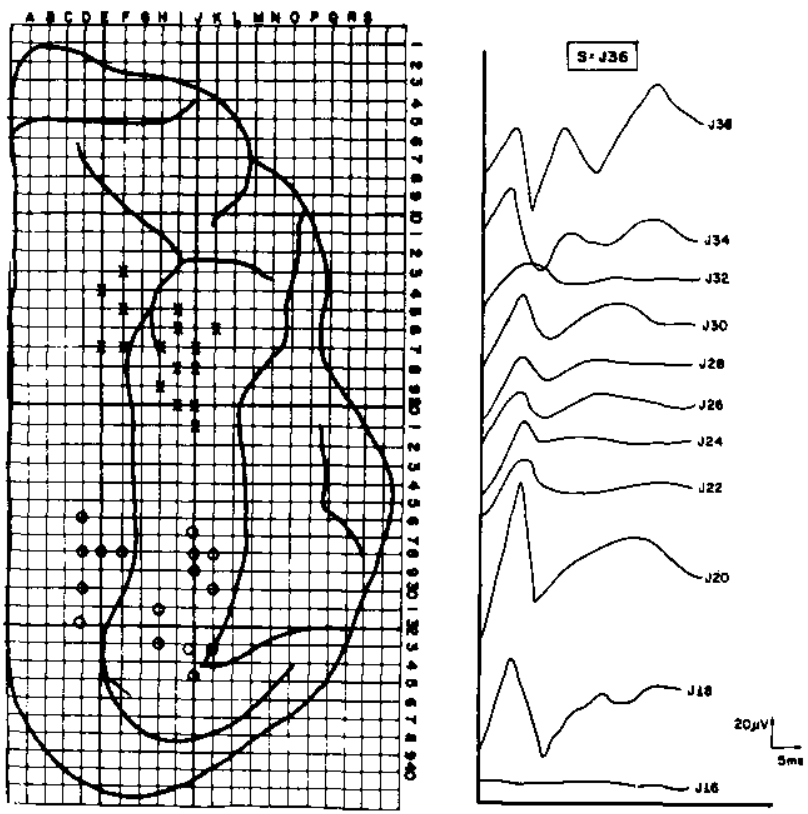

Fig. 1 - Left: May of the cat neocortex as a cartesian matrix stereotaxically design for localization purposes. $\mathrm{O}$ : posteriorly located sites from which stimulation evoked potentials from ipsilateral (x) and contralateral corresponding areas (also defined by ' $x$ '), revealing an L-shaped connection. Right: Time course of the non-symmetrically evoked transcallosal potentials as recorded from the contralateral anterior area. Notice the shift of the higher amplitude zone from J36 to J20. Stimulus at J36. The recording sites are numbered according to the cartesian map at left. 

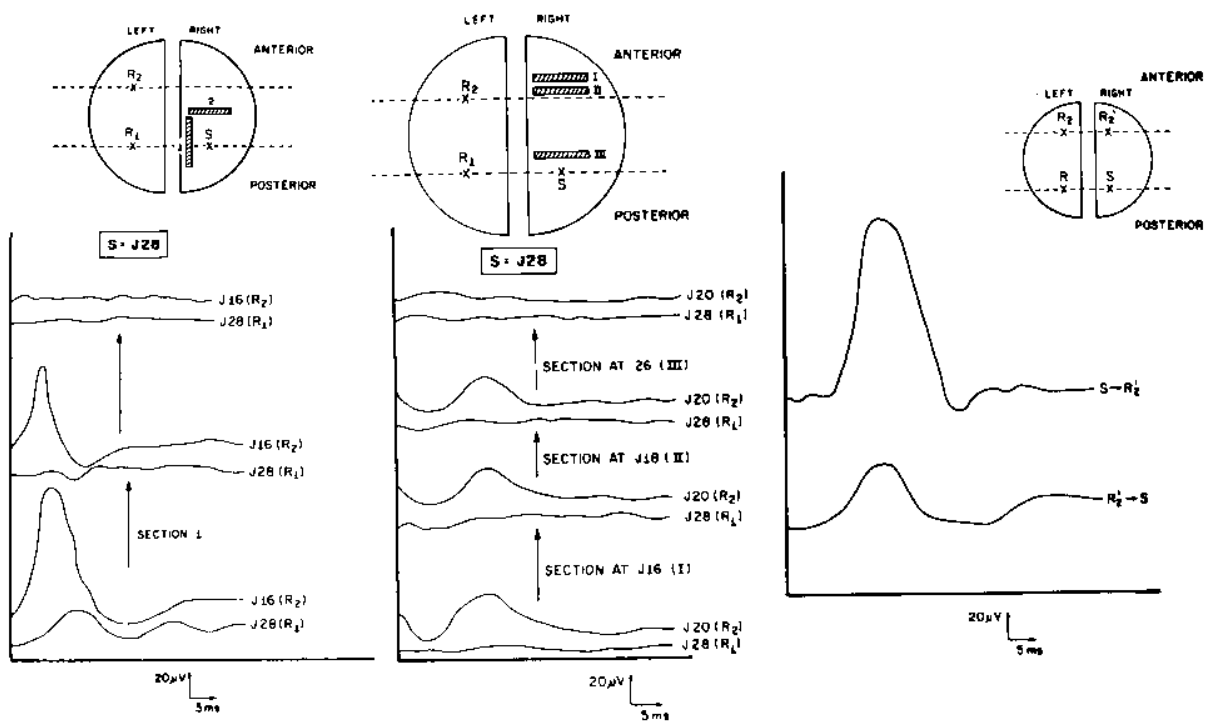

Fig. 2 - Left: Summiry of experiment 1. S (J28), stimulated posterior region. R1(J28), contralateral area homologous to $S$. $R \approx(J 16)$, anterior site from which high amplitude potencials were recorded. Sections 1 and 2 are shown in the upper part of the figure. From bottom upwands: the first pair of traces shows recordings from $R 1$ and $R 2$ before sections 1 and 2 were performed; the intermediate traces show a slight R2 decrease and cessation of response in $R 1$; top traces show a complete disappearance of the response ut $R 2$ after section 2. Middle: Summary of experiment 2. S (J2S), stimulated posterior region. R1 (J28), contralateral area homologous to $S$. $R 2$, anterior site from which high amplitude potentials were evoked. Sections 1,2 and 3 are shown in the upper part of the figure. From bottom upnoards: the first pair of traces shows recondings from $R 1$ and $R 2$ before sections 1,2 and 3 were performed; after section 1 (second pair of traces) and 2 (third pair) the response remuined unchanged; section 3 (fourth pair) abolished R2. Right: Summary of experiment 3. Intrahemispheric recording. $S$, posterior site corresponding to J29. $R$, contralateral area homologous to $S$. $R 2$, anterior site corresponding to $J 18$, which exhibited high voltage response to stimulation at $S$. $R 2^{\prime}$, anterior area corresponding to R2. The lower trace shows the potential evoled on S by stimulating R2'. The upper trace shows the potential evoked from $R \&$ by stimulating $\mathbf{S}$.

\section{COMMENTS}

The experiments above described disclosed the existence of an intrahemispheric connection that links some posterior sites of the cat's neocortex to some anterior sites of the contralateral cortex by means of an L-shaped pathway. The potentials recorded from non-symmetric lateral areas indicate that information from a specific site may be transferred to non-symmetric, distant areas through rather simple pathways. That might be explained by assuming that the thalamus, receiving information from both the ipsilateral and the contralateral cortex, activates the cortical area far from the symmetric locus. There could be a massive oblique callosal interhemispheric pathway between posterior areas of one side and anterior areas of the other or a long intrahemispheric connection linking the posterior to anterior areas in series with a callosal connection to the symmetrical site at the anterior region, thus making up an L-shaped long pathway.

A thalamic mechanism, if involved, would be difficult to recognize in our experiments but it could not be the main mechanism, as shown by the drastic effect of local, shallow longitudinal disconnection between the symmetric (as to the stimulating site) posterior area and the symmetric, anterior area of the contralateral cortex. An oblique, direct connection of the corpus callosum cannot be either invoked to explain the non-symmetric callosal response since anatomical data have shown it to be a comissure with no massive oblique decussations 10. 
The assumption of an intrahemispheric connection linking the ipsilateral posterior and anterior areas was fully demonstrated by the disconnection procedures and the ipsilateral responses evoked by stimulation of both anterior and posterior parts of the cortex. The fact that the potentials evoked in the anterior by posterior stimulation are consistently larger in voltage than those recorded from reciprocal experiments is indicative that there are projection pathways carrying information mainly or only from the posterior to the anterior regions. Potentials in the reverse direction may well be due to antidromic conduction.

The areas thus interconnected coincide with those poorly interconnected by the corpus callosum, revealing the possibility of non-symmetric callosal activation by means of transcallosal pathways (from one side to the other) in series with intrahemispheric pathways in the posterior to anterior direction. However, the evoked potential in R2 in the first percortical section was reduced but did not disappear. This is suggestive that an L-shaped connection made up by the sequence S-R1-R2 carrying concurrent but less information may also exist. Such a connection has already been suggested 12. If this pathway does also exist in man it is probably involved in speech and visuomotor integration.

\section{REF'ERENCES}

1. Avila JO, Radvany J, Huck FR, Camargo CHP, Marino R Jr, Ragazzo PC, Riva D Anterior callosotomy as a substitute for hemispherectomy. Acta Neurochir 30 (Suppl): $137,1980$.

2. Chang HT - Cortical response to activity of callosal neurons. J Neurophysiol 16:117, 1953.

3. Chang HT - Interaction of evoked cortical potentials. J Neurophysiol 16:133, 1953.

4. Cukiert A, Timo-Iaria C - An evoked potential mapping of transcallosal projections in the cat. Arq Neuro-Psiquiat (São Paulo) 47:1, 1989.

5. Curtis H.J - Intercortical connections of corpus callosum as indicated by evoked potentials. J Neurophysiol 3:405, 1940.

6. Curtis HJ - An analysis of cortical potentials mediated by the corpus callosum. J Neurophysiol $3: 414,1940$.

7. Ebner FF, Myers RW - Distribution of colpus callosum and anterior commissure in cat and racoon. J Comp Neurol 124:353, 1965.

8. Hubel $\mathrm{DH}$, Wiesel $\mathrm{TN}$ - Cortical and callosal connections concerned with the vertical meridian of visual fields in the cat. $J$ Neurophysiol $30: 1561,1967$.

9. Luessenhop AJ - Interhemispheric commissurotomy. Am Surg 36:265, 1970.

10. Marcus EM, Watson CW - Bilateral synchronous spike and wave electrographic patterns in the cat. Arch Neurol 14:601, 1966.

11. Poljak S - An experimental study of the association, callosal and projection fibers of the cerebral cortex of the cat. J Comp Neurol 44:197, 1927.

12. Ptito M, Tassinari G, Antonini A - Electrophysiological evidence for interhemispheric connections in the anterior ectosylvian sulcus in the cat. Exp Brain Res 66:90, 1987.

13. Tomasch $J$ - Size, distribution and number of fibers in the human corpus callosum. Anat Rec 119:119, 1954. 